
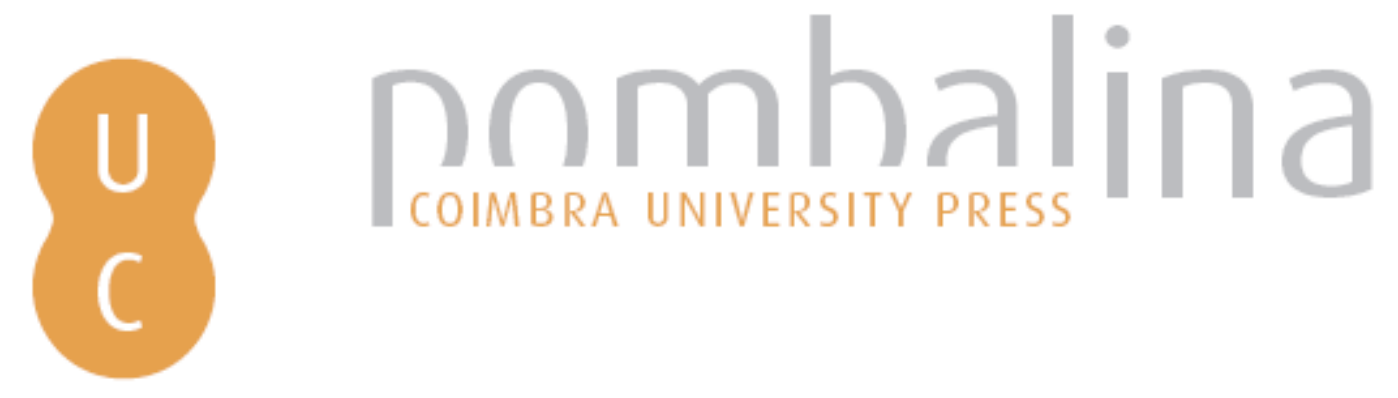

\title{
On the use of time-resolved three-dimensional diagnostics to characterize firebrand showers in the WUI
}

Autor(es): $\quad$ Bouvet, Nicolas; Link, Eric D.; Fink, Stephen A.; Kuligowski, Erica D.

Publicado por: Imprensa da Universidade de Coimbra

URL

persistente: URI:http://hdl.handle.net/10316.2/44608

DOI: DOI:https://doi.org/10.14195/978-989-26-16-506_91

Accessed : $\quad$ 26-Apr-2023 15:16:31

A navegação consulta e descarregamento dos títulos inseridos nas Bibliotecas Digitais UC Digitalis, UC Pombalina e UC Impactum, pressupõem a aceitação plena e sem reservas dos Termos e Condições de Uso destas Bibliotecas Digitais, disponíveis em https://digitalis.uc.pt/pt-pt/termos.

Conforme exposto nos referidos Termos e Condições de Uso, o descarregamento de títulos de acesso restrito requer uma licença válida de autorização devendo o utilizador aceder ao(s) documento(s) a partir de um endereço de IP da instituição detentora da supramencionada licença.

Ao utilizador é apenas permitido o descarregamento para uso pessoal, pelo que o emprego do(s) título(s) descarregado(s) para outro fim, designadamente comercial, carece de autorização do respetivo autor ou editor da obra.

Na medida em que todas as obras da UC Digitalis se encontram protegidas pelo Código do Direito de Autor e Direitos Conexos e demais legislação aplicável, toda a cópia, parcial ou total, deste documento, nos casos em que é legalmente admitida, deverá conter ou fazer-se acompanhar por este aviso.

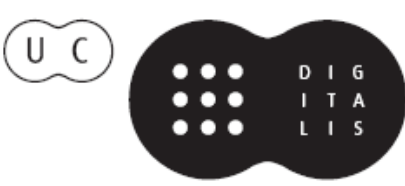




\section{ADVANCES IN}

\section{FOREST FIRE RESEARCH}

\section{8}

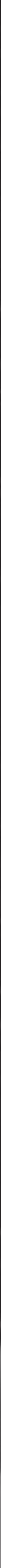




\title{
On the use of time-resolved three-dimensional diagnostics to characterize firebrand showers in the WUI
}

\author{
Nicolas Bouvet*; Eric D. Link; Stephen A. Fink, Erica D. Kuligowski \\ National Institute of Standards and Technology, Gaithersburg, MD, U.S.A. \\ \{nicolas.bouvet@nist.gov*\}
}

\begin{abstract}
A time-resolved, three-dimensional particle tracking and sizing diagnostic (a.k.a "emberometer") is currently being developed. It will be applied to airborne firebrands during wildland-urban interface fires; quantification of firebrand exposures would greatly improve the technical basis for WUI building codes and standards to address ignition vulnerabilities. The present paper provides an overview of the current system and reports test results demonstrating the ability of the system to characterize fluxes of artificially generated airborne firebrands.
\end{abstract}

Keywords: Firebrand; Wildland-Urban Interface (WUI); 3D Particle Tracking Velocimetry (3D-PTV); 3D Particle Shape Reconstruction (3D-PSR); firebrand flux; ember flux.

\section{Introduction}

Firebrands generated from burning wildland and structural fuels are known to be lofted into the air and transported up to thousands of meters from the active fire front (Koo et al. 2010). These firebrands can cause spot-fire ignitions of wildland fuels, as well as ignitions of structures built in the WildlandUrban Interface (WUI) (Maranghides and Mell 2009). Existing WUI-related codes and standards (e.g., NFPA 1144, California Building Code Chapter 7A) lack the research support needed to sufficiently address ignition vulnerabilities in the WUI. A detailed characterization of the exposure from firebrands impacting the WUI (e.g., number/mass flux, particle size distribution, particle temperature, etc.) will provide a more complete definition of the WUI fire hazard (Maranghides and Mell 2013), and the technical basis for further improvements to WUI standards. While conventional measurement techniques have essentially focused on time- and space-averaged post-fire data (El Houssami et al. 2016; Filkov et al. 2017; Thomas et al. 2017), very little is known during an actual firebrand assault. The present work is devoted to the development and validation of a time-resolved, three-dimensional (3D) particle tracking and sizing diagnostic applied to airborne firebrands. Among others, the diagnostic intends to resolve Lagrangian trajectories and speeds of firebrands, as well as reconstruct firebrand shapes in 3D from which characteristic dimensions are extracted.

\section{Experiment}

\subsection{Diagnostic description}

In this work, the motion and size of airborne firebrands are resolved using 3D optical techniques. Firebrand motion is studied via 3D Particle Tracking Velocimetry (3D-PTV) which allows for the time-resolved mapping of individual firebrand trajectories. 3D Particle Shape Reconstruction (3DPSR), following the principles of the visual hull concept (Laurentini 1994), is performed at each time step to yield firebrand characteristic dimensions. The following sections provide an overview of the system being developed as well as succinctly describe core steps involved in each technique.

All uncertainties are reported as expanded uncertainties, $X \pm k u_{c}$, from a combined standard uncertainty (estimated standard deviation) $u_{c}$, and a coverage factor $k=2$ (95\% confidence level, 
assuming normal distribution of the data). Results are shown uncorrected for uncertainty arising from systematic effects.

\subsubsection{Emberometer system 1}

A photograph and a schematic representation of the system are provided in Figure and Figure , respectively. The measurement device, known as the "emberometer", consists of four compact, consumer-grade cameras (Sony DS-RX10 M3) aimed towards the center of a control volume $\left(\sim 2 \mathrm{~m}^{3}\right)$ located about $1.2 \mathrm{~m}$ away from the camera plane. All cameras are operated at minimum focal length $(f=8.8 \mathrm{~mm})$ and largest aperture $(f / 2.4)$. Focus is performed at the center of the control volume, being easily visualized as the intersection of four collimated lasers (CPS series, Thorlabs), carefully aligned during calibration. The cameras simultaneously record High Definition (HD) videos (1080p, $120 \mathrm{~Hz})$ of airborne firebrands traveling within the measurement volume.

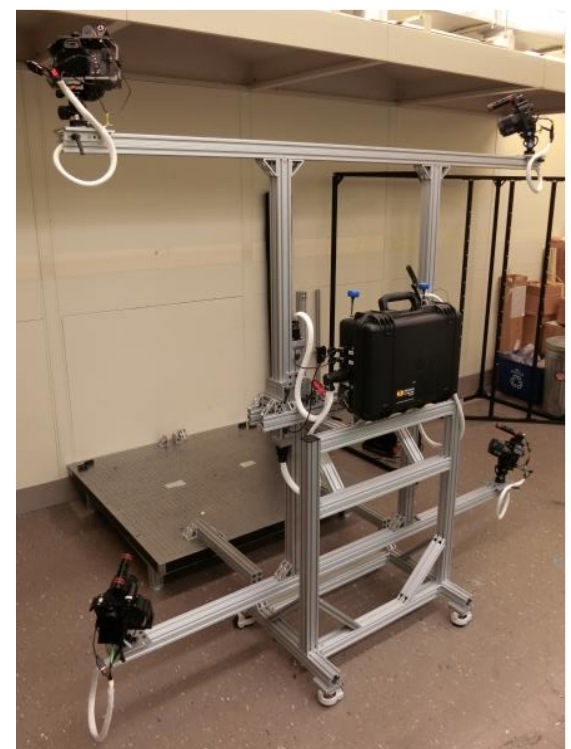

Figure 1 - Photography of the 3D-PTV/PSR system (rear view)

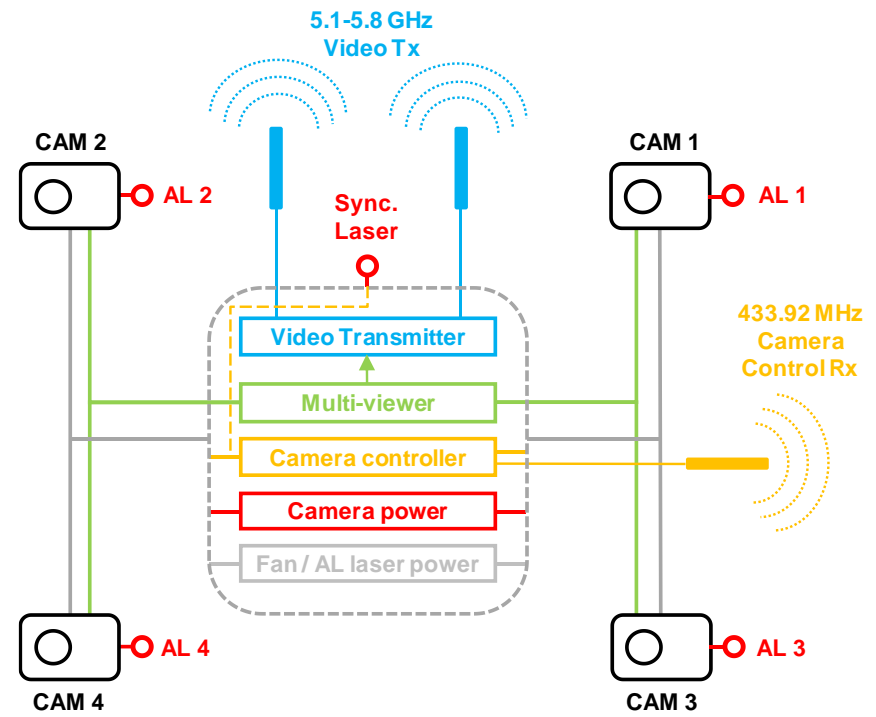

Figure 2 - Schematic representation of 3D-PTV/PSR system (AL.: Alignment Laser)

Camera triggering is achieved via a custom-developed control hub (CAMremote-4CAM, VPSystems) that can be remotely operated by users (RF $433.92 \mathrm{MHz}, \sim 2.4 \mathrm{~km}$ range). The control hub also operates a laser module set to deliver a dot visible from all camera views at the beginning of each recording sequence. The disappearance of the laser dot is used to post-synchronize the video streams across the four cameras in time. This step is essential since each camera has its own response time, even though the initial triggering event is common. Proper video synchronization has been verified by imaging a millisecond counter and is found to be within the time lapse between two consecutive frames.

${ }^{1}$ Certain commercial equipment, instruments, or materials are identified in this paper in order to specify the experimental procedure adequately. Such identification is not intended to imply recommendation or endorsement by the National Institute of Standards and Technology, nor is it intended to imply that the materials or equipment identified are necessarily the best available for the purpose. 
In addition to remote controls, the system is designed to provide a live preview for all cameras, allowing users to monitor image quality and camera settings. To this end, the four video streams are combined into a single HD stream using a quad multi-viewer (Sofly HDSW4-Q). The multi-viewer output is connected to a long range $(\sim 1 \mathrm{~km})$, low latency $(<1 \mathrm{~ms}) \mathrm{HD}$ video transmitter (Amimon Connex, RF 5.1-5.8 GHz) that delivers the video signal to a portable control rig equipped with a parent receiver. In addition to instant monitoring, users have the possibility to remotely record the four camera views at once for troubleshooting purposes. The system electronics are embedded in an air-cooled, ruggedized package to facilitate setup in case of field deployment.

\subsubsection{Emberometer system flowchart}

The simplified flow chart of the system is given in

Figure . Once acquired, video files are converted into color image sequences $(1920 \times 1080 \mathrm{px})$ using a commercial video software. Image sequences are then synchronized and their color space changed to 8-bit grayscale. 3D particle tracking is completed using the open-source software OpenPTV (www.openptv.net). Raw tracking output files are used to generate individual particle identity (PID) files, gathering a time-history of the main particle characteristics (e.g. 3D location, speed, etc.). 3D particle shape reconstruction is then performed for each particle at each time step based on color image information and previously generated PID files. In turn, the PID files are supplemented with size information extracted from the particle 3D models and further used as input for data visualization and analysis. Note that both the tracking and sizing steps require calibration using 3D targets of various nature (not discussed here). All in-house codes are developed using MATLAB and Fortran programming tools.

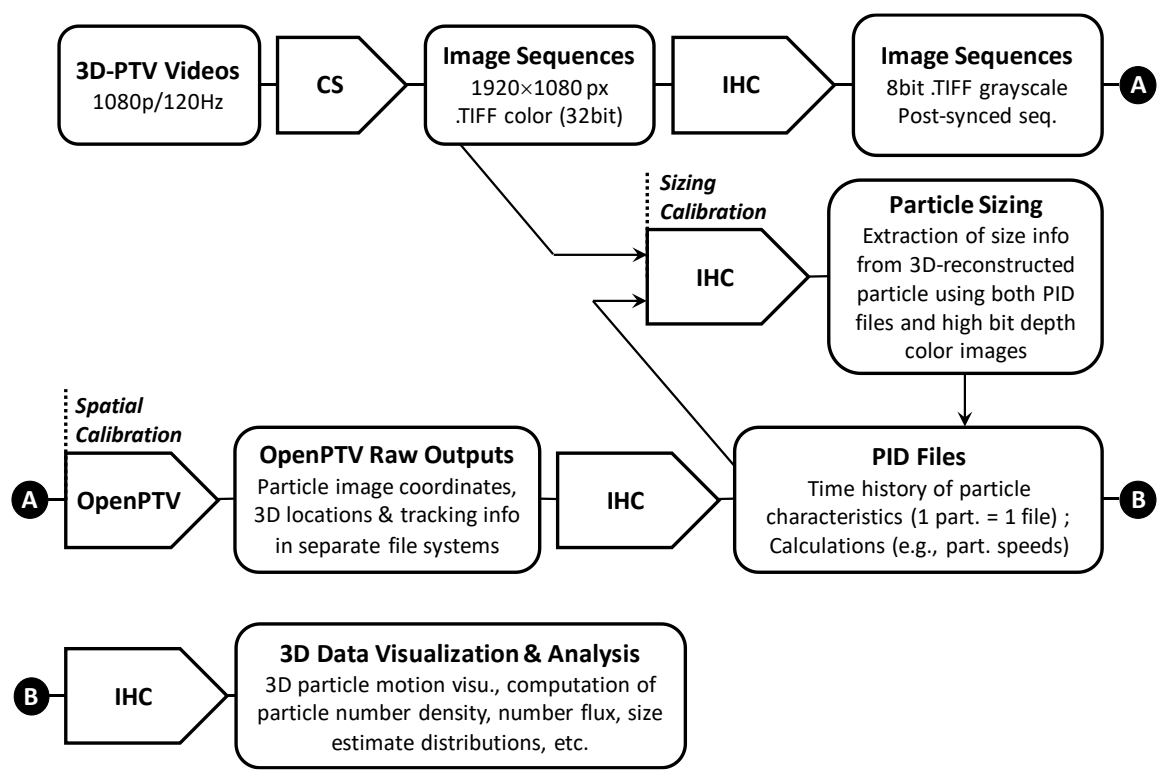

Figure 3- Simplified system flowchart (CS: Commercial Software, IHC: In-House Code)

\subsubsection{D firebrand tracking}

As indicated in the previous section, the 3D tracking of firebrands is computed via the open-source software OpenPTV (www.openptv.net). A detailed description of all operations performed by OpenPTV is clearly outside the scope of the present paper, hence only major steps are mentioned here. The reader is referred to (Willneff 2003) for theoretical insights behind most of these steps, as well as online documentation. The following set of operations are applied:

1- Calibration of the 3D-PTV system: this refers to the 3D spatial calibration of the system. A 3D target is imaged and camera orientation files are generated. These contain essential information related to the camera external parameters (positions and angles of the cameras with respect to 
a chosen referential in the measurement volume) and internal parameters (quantities related to the pinhole model used to represent the cameras, and positioning errors on the camera sensors, for instance due to optical distortions, etc.);

2- Particle detection: particles are detected using an intensity threshold operator. The particle center coordinates (found using a pixel intensity-weighted centroid operator) are listed for each 2D image;

3- Establishing particle correspondences between the different camera views: this is done applying the epipolar line intersection technique, more details can be found in (Luhmann et al. 2014);

4- Computation of $3 D$ coordinates of the particles;

5- Particle tracking: using information found both in the 2D image spaces (2D image from each camera) and 3D object space (previously computed 3D coordinates of the particles).

Steps 1 to 5 allow for the time-resolved mapping of the particle trajectories within the measurement volume. Note that in the present work, airborne firebrands are in the smoldering combustion state and therefore emit a strong orange/yellow light glow. This alleviates the need for illumination usually required in conventional particle tracking experiments to visualize tracers (Mie scattering). Step 2 applies here without any ambiguity, i.e. firebrand are well distinguished from the background elements. An example of a video frame recorded by camera 1 during firebrand generation is given in Figure .

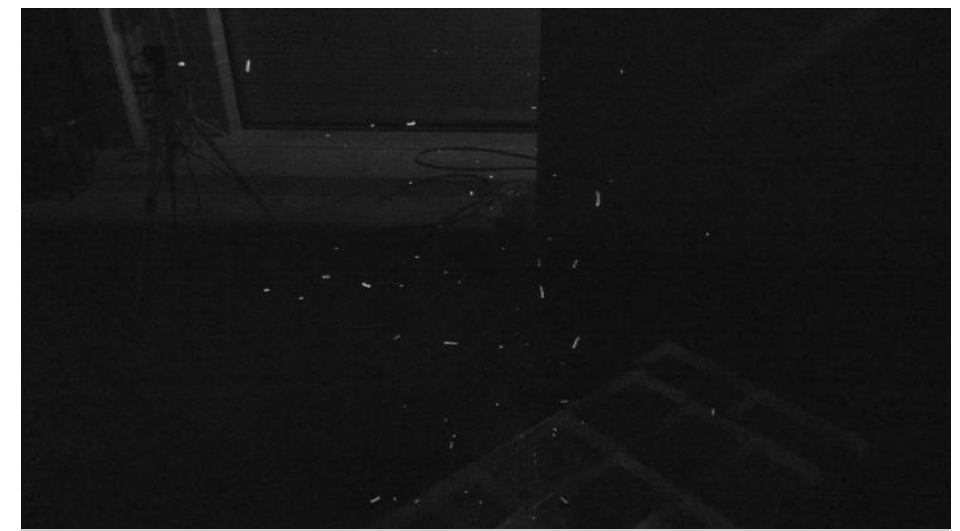

Figure 4 Example of a video frame recorded by camera 1 during firebrand generation (grayscale image).

\subsubsection{D firebrand shape reconstruction}

The 3D firebrand shape reconstruction relies on a multi-projection imaging technique, often referred to as the visual hull method (Laurentini 1994). Various practical implementations of this method have been reported in the literature; the approach adopted in the present work is outlined below. A particle silhouette obtained in a 2D image is back-projected in the measurement space using known camera orientation parameters (obtained from the tracking calibration step) and sizing calibration information. A solid projection cone, taking its origin from the camera optical center and constrained by the contour of the particle back-projected silhouette, can be formed. This process is then repeated from other viewpoints (i.e., in the present case, the 3 other camera views). The intersection of all solid cones created defines the 3D particle shape, which corresponds to the largest volumetric domain that would give identical silhouettes as the particle when observed from each of the different 2D views. A simplified illustration of the methodology is given in Figure for a setup involving 2 cameras. 


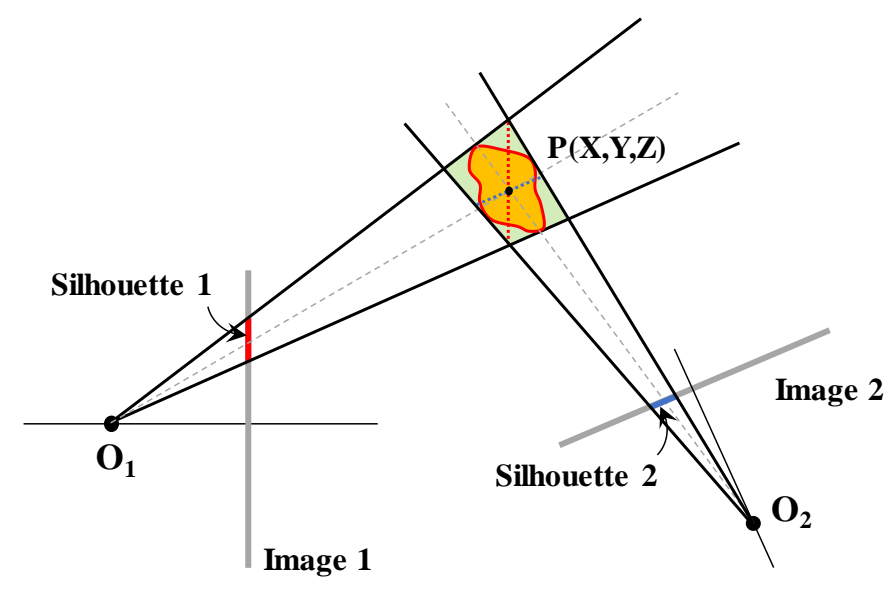

Figure 5 - Simplified 2D sketch illustrating the visual hull method for 3D particle shape reconstruction (only 2 cameras considered here; $O_{i}$ : camera perspective centers, $X, Y$ and $Z: 3 D$ coord. of the particle centroid).

\subsection{Experimental layout and procedure at the National Fire Research Laboratory}

The emberometer was tested at the NIST National Fire Research Laboratory (NFRL). The experimental layout is shown in Figure. The emberometer was set downstream of the output of a firebrand generator. The generator was arranged to produce a flow of glowing firebrands that crossed the calibrated volume of the system. The firebrand generator assembly consisted of a blower (Cincinnati Fan PB-9) connected in line with cylindrical duct elements whose dimensions and arrangement are similar to those used in a previous firebrand study (Manzello et al. 2008). In the present work, the fuel was made of cylindrical birch/maple dowels (diameter: $6.6 \pm 0.3 \mathrm{~mm}$, length: $50.6 \pm 0.1 \mathrm{~mm}$ ) with chamfered edges. The fuel moisture content was measured with a handheld moisture meter (Delmhorst J-2000) and was confirmed to be less than $6 \%$.

The test with firebrands was run as follows: 1) $350 \pm 1 \mathrm{~g}$ of pristine fuel was introduced in the firebrand generator (see picture in Figure ); 2) the blower speed was set to $5 \mathrm{~Hz}$ and two propane torches (Bernzomatic TS8000) were ignited and inserted slightly below the fuel batch, on opposite sides. Ignition was maintained for $45 \mathrm{~s}$; 3) After $45 \mathrm{~s}$, the propane delivery was stopped, and a $15 \mathrm{~s}$ wait time was observed; 4) the blower speed was set to $20 \mathrm{~Hz}$. Shortly after the blower speed increase, a large flame settled at the generator output. The flame length slowly decreased until complete flame disappearance after $\sim 30 \mathrm{~s}$. The first firebrands were produced shortly after the flame onset $(\sim 3 \mathrm{~s})$, and generation continued for about $75 \mathrm{~s}$. The analysis presented in section 3 concentrates on a $33 \mathrm{~s}$ time window (beginning $27 \mathrm{~s}$ after the flame onset), when the peak production of firebrands occurred.

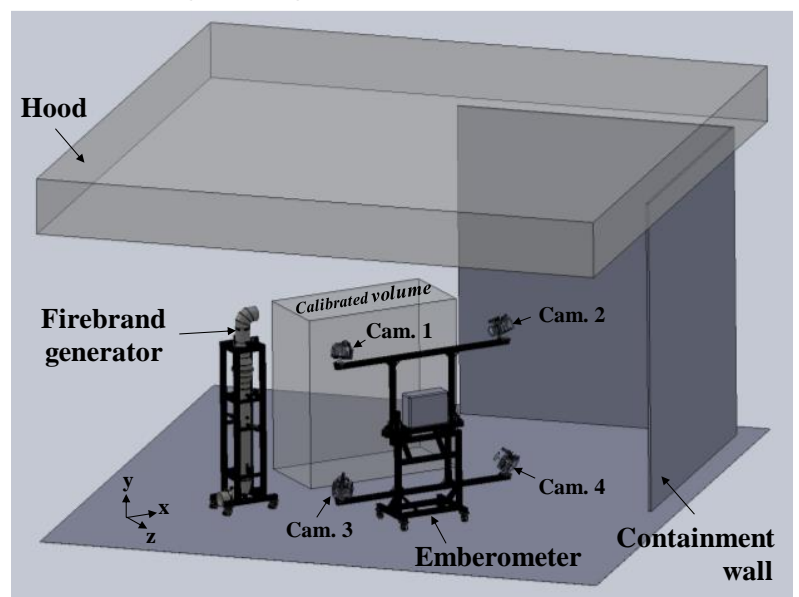

(a)

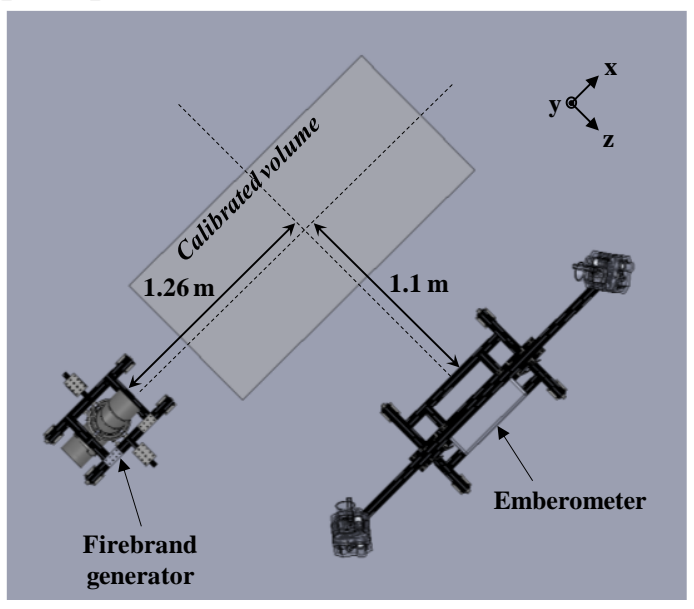

(b)

Figure 6 - Experimental layout for tests at the National Fire Research Laboratory (blower and ignition loop of the firebrand generator not shown here): (a) 3D view; (b) Top view with characteristic dimensions 
Most landing firebrands were collected in aluminum pans filled with water (see arrangement in Figure ) covering an area of about $2.4 \mathrm{~m}^{2}$ and starting $0.56 \mathrm{~m}$ downstream of the firebrand generator exit plane. Collected firebrands were dried and their sizes measured to provide an independent dataset for firebrand size distribution comparison.

Additionally, in-situ validation of the system was performed using non-combusting dowel pieces (sticks identical to those used to generate firebrands) to provide a baseline evaluation of the emberometer measurements with known particles. The sticks were ejected from the firebrand generator without ignition to provide similar trajectories and random behavior as in the combusting case. Sticks were painted white and additional illumination was provided for adequate visibility with the same camera settings as used for combusting particles.

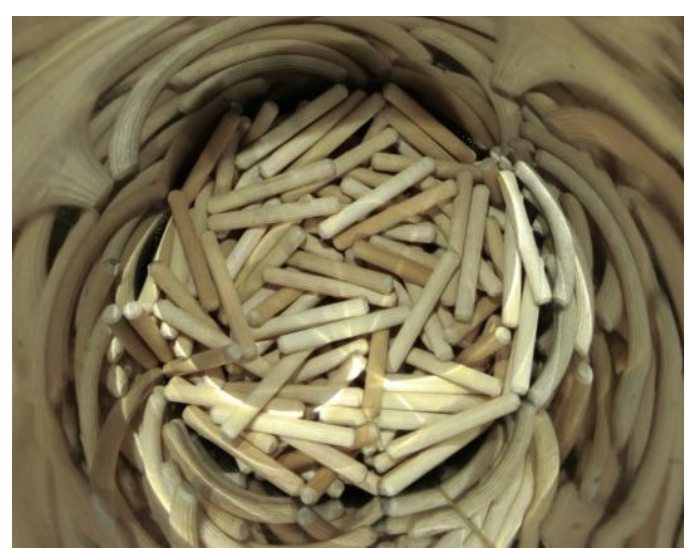

Figure 7 Fuel batch loaded in firebrand generator

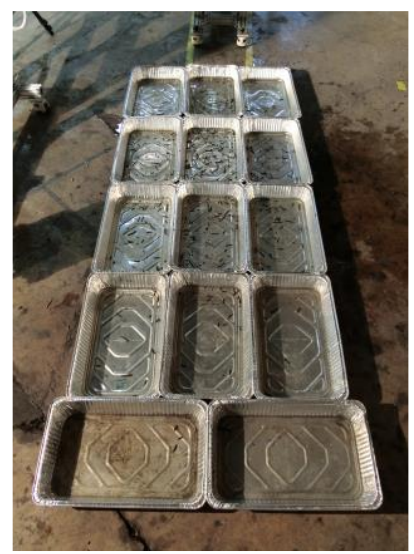

Figure 8 - Water pan arrangement for firebrand collection.

\section{Results}

\subsection{Non-burning sticks}

A total of 43 validation sticks were tracked through the control volume during a $20 \mathrm{~s}$ time period and subsequently reconstructed as described in section 2.1.4. Results of the tracking are shown in Figure. The highlighted plane, chosen to encompass all trajectories, serves as a reference surface for mass flux evaluations.

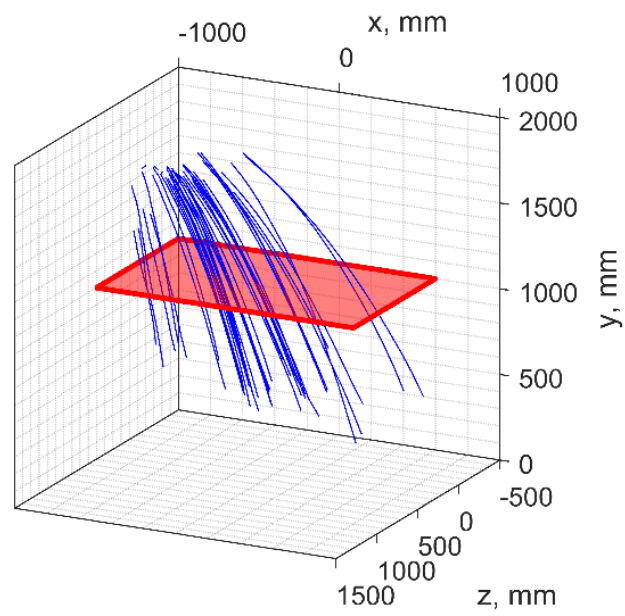

Figure 9 - Tracking results of all 43 validation particles. The highlighted plane was used to evaluate mass flux.

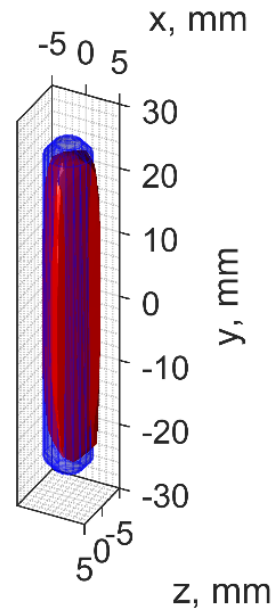

Figure 10 - Example comparison of reconstructed particle (red) with the actual known shape of the noncombusting validation particle (blue). Length $50.6 \mathrm{~mm}$, Diameter $6.6 \mathrm{~mm}$. 
Each of the 43 sticks was reconstructed using the simultaneous camera views as it passed through the control volume. Figure shows an example of a reconstructed particle (red) compared to the true shape (blue) from a single timestep in the video recording. Tracked particles are reconstructed at each timestep. Average shapes and dimensions are obtained by generating cumulative plots of particle edges using all available timesteps (after consistent particle axis re-orientation). Figure shows the resulting orthogonal views of a particle combining each individual measurement of the particle edge (black points). The average measured shape is indicated by the red outline; the blue outline, indicates the true known cylindrical shape.

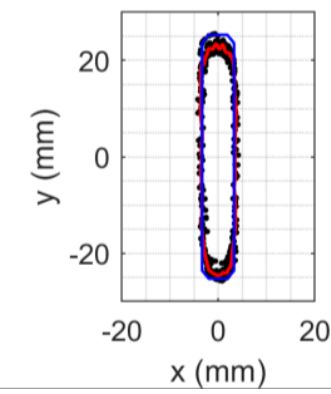

(a)

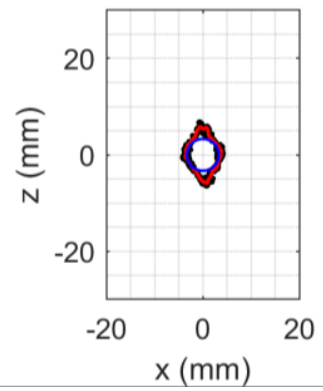

(b)

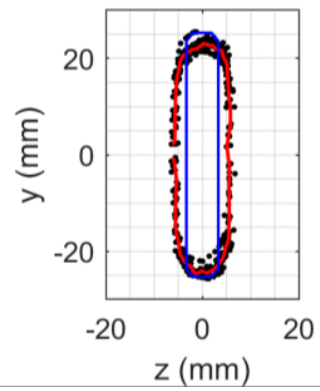

(c)

Figure 11 Orthogonal views of a reconstructed particle show good agreement, particularly in the $x$ - and $y$ directions. Added length is observed in the z-direction due to lack of visibility of the back of particles, increasing the size of the visual hull.

In general, the results are favorable and show good agreement with the true stick dimensions. Figure provides histograms displaying the distribution of dimensions measured for the 43 particles. In each plot, the red line indicates the true particle dimension and the greyed area displays an interval of length corresponding to the expanded measurement uncertainty $\left( \pm k u_{c}\right.$ ). Greatest success is shown for the $x$ and $y$ measured dimensions, where the known dimension falls within the measurement uncertainty. This is not the case, however, for dimensions along the $z$-axis. Clearly, there is a systematic error attributed to the camera configuration and the inability to view behind the particle. Because the particle reconstruction is performed using the visual hull concept, there is additional volume attributed to the particle based on the information that is visible to each camera. A simplified depiction can be seen in Figure where the intersecting cones are larger than the imaged particle. This effect can also be observed in the $z-y$ orthogonal view of the reconstructed particle in Figure c. Characterization of the systematic error is underway to define an appropriate correction method.

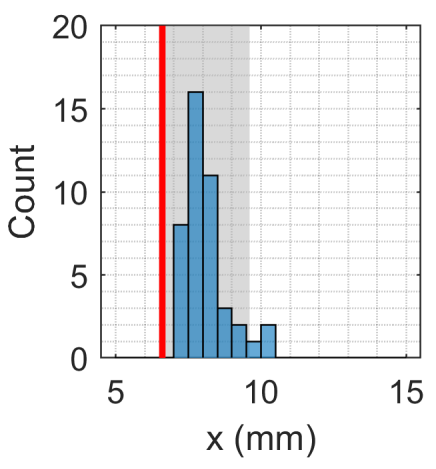

(a)

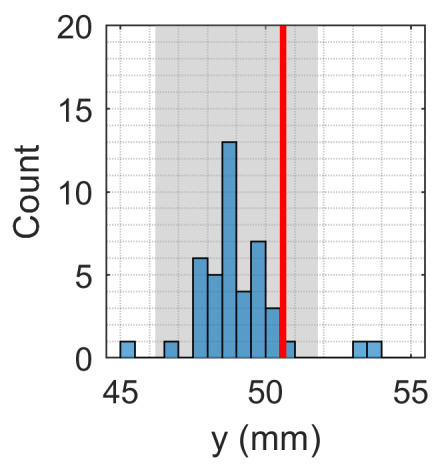

(b)

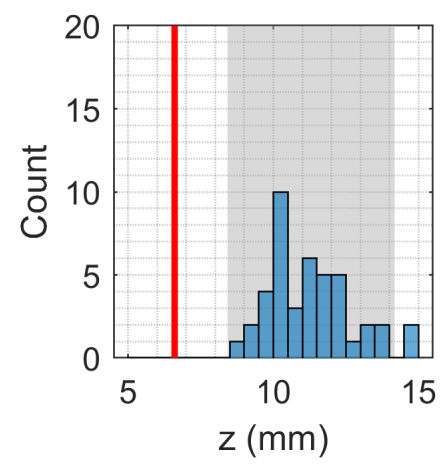

(c)

Figure 12 - Histograms of the measured dimensions of the 43 airborne sticks. Red lines: true stick dimensions; greyed areas: expanded uncertainties $( \pm 1.5, \pm 2.8$ and $\pm 2.9 \mathrm{~mm}$ for $a, b$ and $c$, respectively) 
Knowing the trajectory and volume of each particle allows for the calculation of a cumulative mass of particles (CMP) per surface area given the particle density. In the validation case, the density of the sticks is a known quantity $\left(\rho_{s}=678.7 \pm 60 \mathrm{~kg} \mathrm{~m}^{-3}\right)$, and the CMP per surface area measured by the emberometer (computed using the measured particle volumes and known density) can be compared to its "true" value (using the cumulative number of particles and known average particle mass). Figure shows results for both calculations using the reference surface specified in Figure .

The blue line plots the cumulative number of particles per unit area during the analyzed time period and is read on the left axis. The other three lines relate to the CMP, and are read to the right axis. The actual CMP is known based on the true mass of the particles (green line). The solid red line plots the emberometer measured CMP based on the reconstructed particle volume and density. As previously noted, the volume measurement is overestimated, resulting in a corresponding overestimate of the CMP. It is observed that correcting the emberometer CMP by the ratio between the actual and average measured particle volumes (i.e., a constant factor equal to 0.751) is sufficient to collapse the measured CMP to the actual CMP. Assuming CMP linearity vs. time, the mean measured mass flux, i.e. $2.05 \pm 0.66 \mathrm{~g} \mathrm{~m}^{-2} \mathrm{~s}^{-1}$, closely collapses onto the actual mass flux, $1.55 \pm 0.19 \mathrm{~g} \mathrm{~m}^{-2} \mathrm{~s}^{-1}$. The constant correction factor result, while remarkable, is not intuitive, as it is independent of individual particle position or orientation within the control volume. Additional work is planned to better characterize the volume errors.

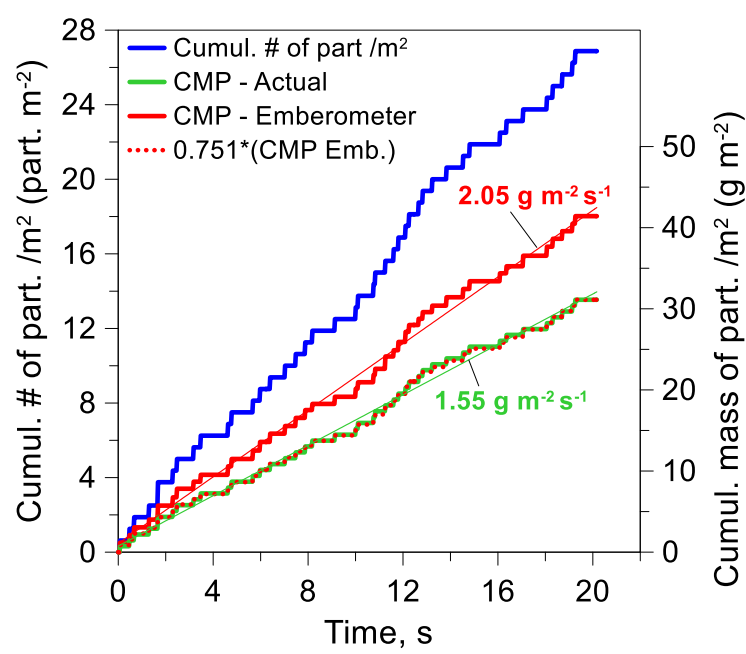

Figure 13 Cumulative number and mass of particles (non-burning stick case). CMP plot labels indicate the emberometer (red) and actual (green) mass fluxes, respectively.

\subsection{Firebrands (Burning sticks)}

Actual combusting firebrands were generated using dowel pieces with the same dimensions as the non-combusting validation case. Glowing/smoldering firebrands were directed into the control volume following the procedure highlighted in section 2.2. The complete tracking results are shown in Figure , along with the designated area used for flux calculations. A total of 1032 particles were tracked and measured during the test. 


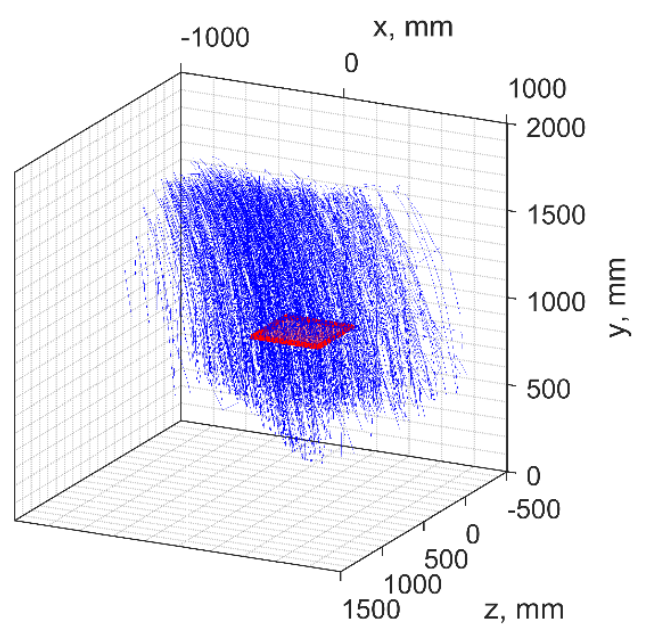

Figure 14 - Firebrands tracked through the control volume $(N=1032)$.

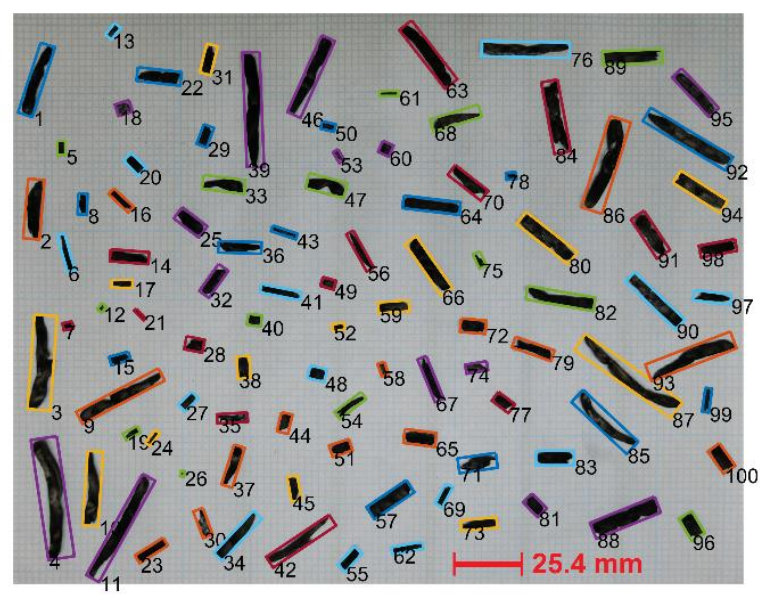

Figure 15 - Burning sticks were captured and quenched in pans of water. Dimensions of each captured firebrand $(N=$ 1155) were measured using a calibrated image.

Additionally, the firebrands were captured and quenched in pans of water arranged on the floor for subsequent counting and measuring. After the test, accumulated firebrands were dried and positioned for photographs. Calibrated images were used to measure 1155 recovered particles using an in-house analysis script. A selection of recovered firebrands is seen in Figure, along with the bounding boxes used to automatically evaluate the dimensions of each particle. Although care was taken during firebrand collection, transport, drying, and photographing, it is acknowledged that some pieces may have broken/spalled into multiple smaller pieces, and that some pieces may have been discarded. It is not possible to account for these effects; however, the authors believe the sample to be representative of the firebrands that landed in the water pans. Limitations of this image-based measurement method include the characterization of particle width, particularly for the longer curved particles (e.g. particle \#4 of Figure ). The bounding box was aligned with the longest axis, and was determined as the smallest bounding rectangle. This method is comparable to the sizing method based on the orthogonal views of the emberometer reconstructed particles, as presented in Figure .

Histograms of the firebrand size distributions are shown in Figure . Distributions for both the collected firebrands and airborne emberometer measurements are compared, normalized by the total number of firebrands collected by each method. Blue bars correspond to the collected firebrands while the orange bars correspond to emberometer measurements of airborne firebrands. Figure a shows the distribution of the long dimension. It is observed that the combustion and forced ejection processes of the firebrand generator significantly alter the dimensions of the particles, and there is a significant number of shorter particles compared to the initial length. Very good agreement is observed between the two measurement methods, as the distributions overlap. In both cases, there is the potential limitation of undercounting the smallest firebrands, particularly as the tiny brands may be buoyant enough to escape the emberometer control volume, as well as the collection pans, as they are transported out through the exhaust hood. 


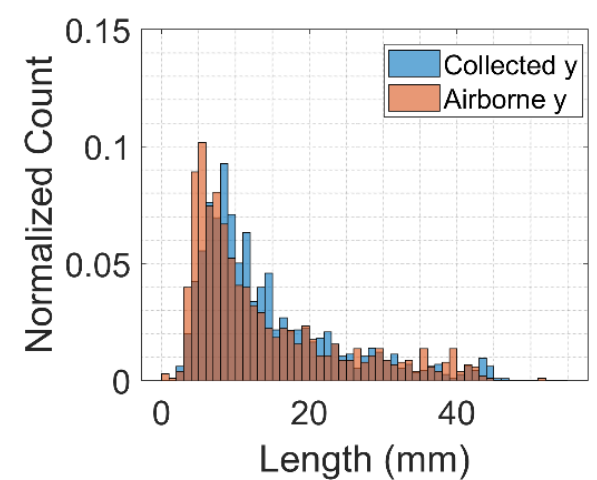

(a)

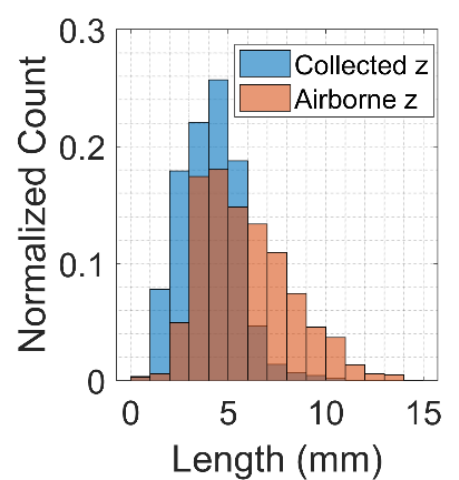

(b)

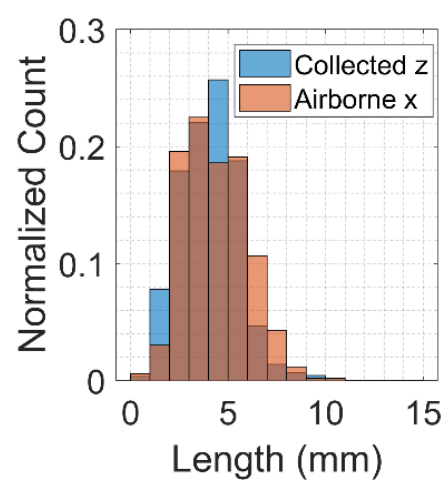

(c)

Figure 16 Distribution of firebrand dimensions as measured by the emberometer compared to those physically collected in the water pans. Bars are normalized by number of brands in each sample, bins are increments of 1 mm. Uncertainties are expected to be on the order of those presented in Fig. 12

An additional limitation is that sizing the quenched firebrands using the imaging technique yields only two dimensions. For comparison to the emberometer measurements, the appropriate dimension should be selected. Based on the orientation of the collected particles in the photographs, the corresponding view is of the $y-z$ plane, along the $\mathrm{x}$-axis (i.e. the two longest dimensions are visible). This comparison is presented in Figure 16b. It is noted that the error in the emberometer measurement systematically overpredicts the particle size in a similar manner as to the error observed in Figure 11c. In the current case, the collected particles can be assumed to have comparable dimensions along the $\mathrm{x}$ and $y$ axes (based on their original shapes), thus the $\mathrm{x}$-dimension is likely to provide a better measurement of the short dimension of the firebrands. The $\mathrm{x}$-dimension of the particle is plotted in Figure 16c, and shows better agreement with the collected firebrand size distribution.

As was done for the validation case, the flux of firebrands was also considered in the combusting case. Due to the current limitations regarding the reconstructed volume accuracy, only the number flux of firebrands is presented here. In future work, improved characterization of particle volume errors will reduce the uncertainty in mass flux measurement. However, the number flux of particles is measurable now, and is presented in Figure 17. The black points correspond to the cumulative number of particles passing through the designated area, and is read to the left axis. The red line corresponds to the number flux as a function of time, and is read to the right axis. The fluctuations in number flux are confirmed to correlate with visually observed fluctuations in firebrand generation during the test.

\section{Conclusion}

A unique methodology for the measurement and characterization of firebrand showers was tested using both non-combusting validation particles as well as glowing firebrands. Overall, measurements of airborne firebrand dimensions agree well with validation particles and physically collected quenched firebrands. The true dimensions of validation particles are within the uncertainty of the measurement of the longest ( $y$-axis) and shortest ( $x$-axis) dimensions of particles. Due to the configuration of the cameras, the third dimension $(z-$ axis), and consequently the particle volume, shows higher deviation from the known value.

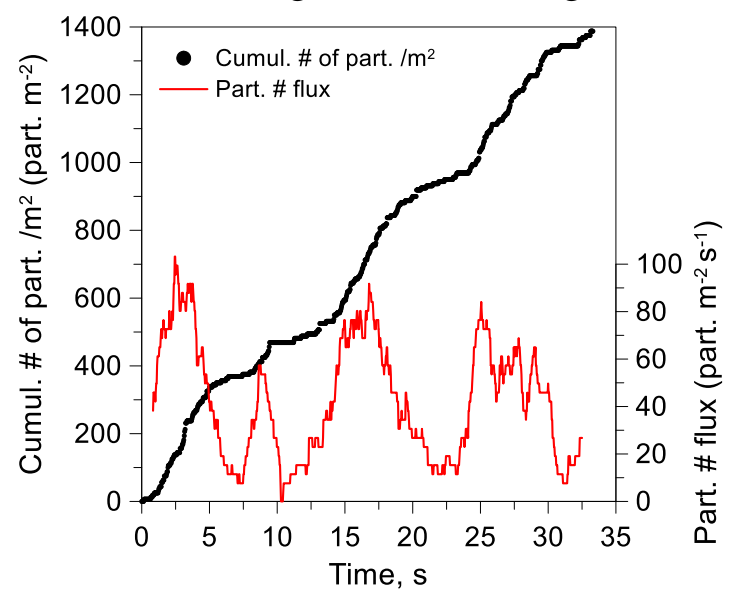

Figure 17 - Cumulative number of firebrands (per $m 2$ ) and the number flux of firebrands during the test period. 
More analysis is required to improve the particle volume measurement of airborne firebrands, which will more accurately measure mass flux. However, in the validation case, where mass flux was independently measured, a constant volume correction factor adequately recovers the true mass flux.

Future work regarding the emberometer includes improved characterization of measurement errors and camera configurations, as well as deployment considerations for measurement of firebrands from actual wildland urban-interface fires. These future measurements may be used to better understand the true exposure conditions experienced from WUI fires and can be related to structure ignition mitigation as well as fire spread and spotting predictions.

\section{Acknowledgments}

The authors would like to thank Ed. Hnetkovsky for machining various parts for the system. Technical support by the NFRL personnel is also gratefully acknowledged.

\section{References}

El Houssami, M, Mueller, E, Filkov, A, Thomas, JC, Skowronski, N, Gallagher, MR, Clark, K, Kremens, R, Simeoni, A (2016) Experimental Procedures Characterising Firebrand Generation in Wildland Fires. Fire Technology 52, 731-751.

Filkov, A, Prohanov, S, Mueller, E, Kasymov, D, Martynov, P, Houssami, ME, Thomas, J, Skowronski, N, Butler, B, Gallagher, M, Clark, K, Mell, W, Kremens, R, Hadden, RM, Simeoni, A (2017) Investigation of firebrand production during prescribed fires conducted in a pine forest. Proceedings of the Combustion Institute 36, 3263-3270.

Koo, E, Pagni, PJ, Weise, DR, Woycheese, JP (2010) Firebrands and spotting ignition in large-scale fires. International Journal of Wildland Fire 19, 818-843.

Laurentini, A (1994) Visual hull concept for silhouette-based image understanding. IEEE Transactions on Pattern Analysis and Machine Intelligence 16, 150-162.

Luhmann, T, Robson, S, Kyle, S, Boehm, J (2014) 'Close Range Photogrammetry and 3D Imaging.' (Walter De Gruyter GmbH: Göttingen)

Manzello, SL, Shields, JR, Cleary, TG, Maranghides, A, Mell, WE, Yang, JC, Hayashi, Y, Nii, D, Kurita, T (2008) On the development and characterization of a firebrand generator. Fire Safety Journal 43, 258-268.

Maranghides, A, Mell, W (2009) A Case Study of a Community Affected by the Witch and Guejito Fires. National Institute of Standards and Technology, NIST Technical Note 1635.

Maranghides, A, Mell, W (2013) Framework for Addressing the National Wildland Urban Interface Fire Problem - Determining Fire and Ember Exposure Zones using a WUI Hazard Scale. National Institute of Standards and Technology, NIST Technical Note 1748.

Thomas, JC, Mueller, EV, Santamaria, S, Gallagher, M, El Houssami, M, Filkov, A, Clark, K, Skowronski, N, Hadden, RM, Mell, W, Simeoni, A (2017) Investigation of firebrand generation from an experimental fire: Development of a reliable data collection methodology. Fire Safety Journal 91, 864-871.

Willneff, J (2003) A spatio-temporal matching algorithm for 3D particle tracking velocimetry. Ph.D. thesis, Swiss Federal Institute of Technology Zurich. 